\title{
Relationship between the value of child and postpartum depression in women referring to Bam healthcare centers
}

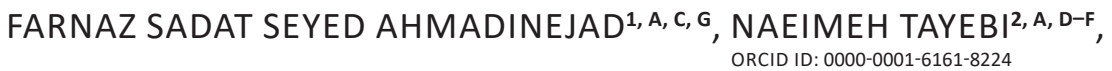 \\ ZAHRA KARIMI DASTENAEI ${ }^{3, \text { в, F, NILOUFAR IZADDOOST }}$ 3, в, F \\ ORCID ID: 0000-0002-4514-7423
}

${ }^{1}$ Department of Midwifery, Facaulty of Nursing and Midwifery, Kerman Branch, Islamic Azad University, Kerman, Iran
2 Department of Midwifery, School of Nursing and Midwifery, Bam University of Medical Sciences, Bam, Iran
${ }^{3}$ Student Research Center, School of Nursing and Midwifery, Bam University of Medical Sciences, Bam, Iran

A - Study Design, B - Data Collection, C - Statistical Analysis, D - Data Interpretation, E - Manuscript Preparation, F - Literature Search, G - Funds Collection

Summary Background. Depression is one of the most common psychiatric disorders in almost all countries and cultures. Stressing factors are also involved in the development of depression. Postpartum depression may lead to problems for the mother, infant and other family members. The value of children has a direct effect on fertility behaviors.

Objectives. The aim of this study was to determine the relationship between a child's value and postpartum depression.

Material and methods. In this cross-sectional study, 260 primiparous women were selected randomly in 2015-2016 in Bam, Iran, after eight weeks of childbirth. The Demographic Questionnaire, Nauck and Troomsdorff Questionnaire of Value of Children and Edinburgh Postnatal Depression Questionnaire were the completed. The collected data was analyzed by SPSS software version 18 and by using the Kolmogorov-Smirnov test, Pearson, Spearman correlation coefficient, Chi-square and regression analysis. The $p$-value was considered as less than 0.05 .

Results. There was no significant relationship between postpartum depression and the emotional dimension $(p=0.513)$ of a child's value, but there was a significant relationship between the social $(p=0.012)$ and economic $(p=0.001)$ dimensions of a child's value. There was a significant relationship between postpartum depression and the mother's education $(p=0.046)$, economic situation ( $p=$ $0.012)$, type of pregnancy $(p<0.001)$ and delivery method $(p<0.001)$.

Conclusions. As to the finding, postpartum depression was influenced by the social and economic dimensions of a child's value and demographic factors. By paying attention to these factors, we can implement proper interventions in order to promote personal and social health among women.

Key words: child, postpartum depression, women.

Ahmadinejad FSS, Tayebi N, Dastenaei ZK, Izaddoost N. Relationship between the value of child and postpartum depression in women referring to Bam healthcare centers. Fam Med Prim Care Rev 2021; 23(4): 400-405, doi: https://doi.org/10.5114/fmpcr.2021.110351.

\section{Background}

According to WHO (World Health Organization), postpartum mental health has been reported as a major public health issue; at least one out of ten women experience serious mental disorders during pregnancy or one year after childbirth [1].

Depression in women is more common than men for reasons such as hormonal changes in the menstrual cycle, pregnancy and menopause [2]. Although pregnancy and childbirth are considered as physiological events which are pleasant in most cases, they are sometimes accompanied by mental side effects that can be dangerous for the mother and infant if ignored [2-5].

Postpartum depression may begin up to the first 4 weeks after childbirth, though some studies have reported its onset up to 12 months after childbirth [6].

The prevalence of postpartum depression in the first few weeks after childbirth has been reported to be $15 \%$, and in specific situations, it has been reported to be up to $41 \%$ [7].

Depression with an adverse effect on the ability of the mother's self-care may lead to problems such as inadequate nutrition, drug abuse and irregular visits to treatment centers [8]. Postpartum depression increases the risk of major depressive episodes in life [9]. This situation may affect the amount of maternal and infant attachment and other family relationships, and it may even threaten the safety and health of the mother, infant and other children [10, 11].
The prevalence of depression, especially postpartum depression, is closely related to cultural and social factors; therefore, its prevalence varies from country to country [12].

Society pays particular attention to the birth of children and their nurturing. Childbirth is also of fundamental importance for parents at the micro level of the family. There are many factors influencing the parents' intention to have a child. Having a child is considered as a natural part of adult life, including raising and educating children, sharing a life with them and taking responsibility for their happiness and well-being. Individual motivations for having a child are related to family, emotional and social goals and thus provide socio-cultural factors, structural conditions and background factors for having or not having a child. These factors are also related to social beliefs and values about having children, the number of children, the individual acceptance of values and norms and cultural beliefs [13].

In Iranian society, children are traditionally considered to be divine gifts, and their presence is normal and anticipatory, while their absence has to be explained. In Iranian culture, proverbs such as 'unmarried couples are like fruitless trees' show that children are the center of the family and cause solidarity within the family structure [14].

The concept of child's value is form according to the structure of different communities and families, and the socio-psychological characteristics of individuals, and reflects the differences in 
reproductive behaviors in different cultural contexts [13-16]. In fact, the concept of "value of children" is a cost-benefit model that helps to understand more intercultural differences, and it emphasizes the importance of social structure [17].

Studies categorized a child's value in three dimensions, including emotional-mental values (i.e. having someone to love and take care of the child, the pleasure of watching children growth and having emotional relationships with one's children), economic-utilitarian values (e.g. helping the household economy, helping out at home and helping an providing security when parents are old) and social-normative values (e.g. continuation of a generation and its surname and promotion of parental status among close relatives) $[15,16]$.

Studies show that in many cultures, the importance of the emotional dimension of a child's value is independent of economic development [18]. Due to the impact of various factors, such as industrialization, modernization and increased income levels on the value of children, the importance of the dimension of the economic-utilitarian value of a child decreases every day [13].

Shahnoushi et al. concluded that the value of children in rural and urban households was not equal, while the variables of the economic, financial and security values of the child, defining oneself by one's child's position, family continuity, physical labor and sexual preferences affected the difference in the value of children in urban and rural areas. However, the economic attitude towards a child has become obsolete among rural households [19].

Considering the fact that the postpartum period can be so stressful that it causes psychological illnesses and with regard to the involvement of the cultural and social issues governing societies in the emergence of depression, we can find out whether the importance of a child's value is involved in the incidence of postpartum depression or not. Since, despite the widespread search of data sources, there were no similar studies conducted in this area, it is hoped that this study will help to find one of the risk factors for postpartum depression.

\section{Objectives}

The purpose of this study was to determine the relationship between a child's value and postpartum depression in women referred to health centers.

\section{Material and methods}

\section{Study design}

This study was a cross-sectional study conducted in 2015-2016 (11 months).

\section{Study setting}

This study took place in health centers affiliated with Bam University of Medical Sciences, Iran, by random sampling starting in winter 2015 and ending in fall 2016.

\section{Study population}

The study population consisted of all primiparous women referred to Bam healthcare centers in the south of the Kerman province.

\section{Sample size estimation}

During an extensive search of data sources, no similar study was found. After conducting a pilot study on 30 subjects, with a $95 \%$ confidence interval $(\alpha=0.05)$ and the power of $80 \%(\beta=$ 0.2 ), the appropriate sample size was calculated as 260 cases. Taking into consideration $10 \%$ of the sample loss, 290 people were included in the study. Out of this number, 30 cases were excluded from the study due to not responding to at least $20 \%$ of the questions, and finally, 260 people were examined.

$$
\begin{aligned}
& N=\left(\frac{\left(z_{1-\frac{\alpha}{2}}+z_{1-\beta}\right)}{c(r)}\right)^{2}+3 \\
& C^{(r)}=\frac{1}{2} \log \left(1+\frac{r}{1-r}\right) .
\end{aligned}
$$

\section{Selection criteria}

The study inclusion criteria are: Iranian women living in Bam city, 18-35 years of age, primipara women, having singleton infants, eight weeks postpartum, BMI less than $26 \mathrm{~kg} / \mathrm{m}^{2}$, not using medicine, not having chronic illness (underlying diseases including diabetes, cardiovascular disease, hypertension, epilepsy, migraine, thyroid disease, connective tissue disease, asthma, kidney disease, anemia), no history of abortion, no history of infertility or high risk pregnancy (hypertension in pregnancy and preeclampsia, eclampsia, bleeding, premature uterine contractions, fetal abnormalities, intrauterine growth restriction, placental abruption, placenta previa), no history of depression before pregnancy and during pregnancy, non-occurrence of life-threatening events (death of a family member, family member illness, financial problems, accidents, subjects or their spouse being fired or losing job, family disputes) over the past six months. The study exclusion criteria are: Occurrence of crisis or stressful incidence, woman's desire to leave the study, preterm delivery, sick neonate, infant weight less than 2500 grams, having a history of emergency cesarean section and difficulty delivery.

\section{Sampling technique}

In the first step, a simple random sampling method was used to select three out of eight health centers in Bam city by drawing lots. Then two days of the week were selected randomly for sampling by drawing. The women eligible for the study were included by simple non-probabilistic sampling after explaining the goals and method of the study and obtaining written informed consent. The present study was conducted after obtaining the permission of the deputy research director, confirmation of the Ethics Committee, coordination with the city's health centers, receiving a referral from the security center, presenting it to authorities of the healthcare centers and coordinating the time of distribution of the study tools.

\section{Data sources/measurement}

Women who were eligible for the study and who referred to the health center for vaccination of their two-month-old child completed an informed consent form before their child was vaccinated. The researcher, after examining the study inclusion and exclusion criteria and presenting the goals of the study, asked the study subjects to complete the Individual and Midwifery Information Questionnaire, Nauck and Troomsdorff (2005) Questionnaire of Value of Children and Edinburgh Postnatal Depression Questionnaire. The Individual and Midwifery Information Questionnaire included questions about individual characteristics and ob/gyn information in addition to disease records completed by the research unit.

The Nauck and Troomsdorff (2005) Questionnaire of Value of Children included 27 items and was measured by a 5-point Likert scale from "not at all important" to "very important". The obtained results were categorized in three dimensions of emotional (5 items), economic (12 items), social-normative (10 items) Benefits. The score obtained in each dimension was determined based on the mean value. Higher scores indicated the value of more children in the relevant dimension. The validity of research using content validity and reliability of the method and internal consistency was determined by calculating Cronbach's alpha $(r=0.85)$. 
The Edinburgh Postnatal Depression Questionnaire was made from ten multiple-choice questions on a 4-point Likert scale, and each question had a score of 0 to 3 . This standard questionnaire was confirmed for the evaluation of postpartum depression. A score 10 or more in this questionnaire showed postpartum depression, and a score of less than 10 indicated a normal person in terms of postpartum depression. The formal and content validity and reliability of the Persian version of this questionnaire was confirmed by Montazeri et al. in 2007 [20]. The test-retest reliability with a correlation coefficient of 0.80 was applied to confirm the reliability of the questionnaire [15]. In the present study, the reliability was calculated, and the Cronbach's alpha was 0.71 . The average length of time for answering questions was 15 minutes.

\section{Data analysis}

In addition, it was stated that all information would remain confidential. Data was collected using SPSS software (version 16), and descriptive and inferential statistics were used to analyze the data. Data were analyzed using descriptive and inferential statistics, Kolmogorov-Smirnov, $t$-Test or Mann-Whitney test, Chi-square test and regression analysis.

\section{Ethical consideration}

This research project was approved by the local Ethics Committee of Bam University of Medical Sciences (MUBAM. REC.1395.2.). Additionally, before the start of the study, informed consent was given by the participants. The participants were assured of the confidentiality of all their personal information. The researchers tried to observe all of the participants' rights in accordance with the declaration of Helsinki. The research proposal number is 1395.2 .

\section{Results}

\section{Participants}

In this study, 260 women with an age range of $16-35$ years and mean age of 25 were studied. Among the women, 91 (35\%) had a high school diploma, and 195 (75\%) were housewives. The average number of female children in the study population was $102(39 \%)$, and the average number of male children was $158(61 \%)$.

\section{Main results}

This study showed that $36 \%$ of the subjects presented postpartum depression. Table 1 shows the coefficients of the regression model between postpartum depression and the child value dimensions. According to this table, the social and economic dimensions of child's value were determined to be significant at a level of 0.05 . These dimensions are good predictors of postpartum depression, but the emotional dimension of a child's value is not significant at a level of 0.05 . Table 2 shows the social dimension, with a mean of $2.97 \pm 0.6$ being the lowest dimension of child value, and the emotional dimension, with a mean of 3.79 \pm 0.42 being the highest dimension of child value in this study.
Table 3 shows the effect of demographic variables on the value of a child and postpartum depression. According to this table, the type of pregnancy and delivery method affects the value of a child and postpartum depression. The mother's education and economic status also affect postpartum depression.

\begin{tabular}{|l|l|l|l|l|l|}
\hline \multicolumn{6}{|l|}{ Table 1. Coefficients of the regression model between postpar- } \\
tum depression and child value dimensions \\
\hline Variable & $\begin{array}{l}\text { Non-stan- } \\
\text { dard coef- } \\
\text { ficient }\end{array}$ & $\begin{array}{l}\text { Standard } \\
\text { deviation }\end{array}$ & $\begin{array}{l}\text { Standard- } \\
\text { ized coef- } \\
\text { ficient }\end{array}$ & $\begin{array}{l}t \text {-Test } \\
\text { stats }\end{array}$ & $p$ \\
\hline $\begin{array}{l}\text { Width from } \\
\text { origin }\end{array}$ & -0.867 & -0.327 & - & -2.649 & $0.009^{*}$ \\
\hline $\begin{array}{l}\text { Emotional } \\
\text { dimension } \\
\text { of child } \\
\text { value }\end{array}$ & -0.045 & 0.068 & 0.038 & -0.655 & 0.513 \\
\hline $\begin{array}{l}\text { Economic } \\
\text { dimension } \\
\text { of child } \\
\text { value }\end{array}$ & 0.287 & 0.073 & 0.294 & 3.924 & $0.001^{*}$ \\
\hline $\begin{array}{l}\text { Social } \\
\text { dimension } \\
\text { of child } \\
\text { value }\end{array}$ & -0.194 & 0.076 & -0.231 & -2.545 & $0.012^{*}$ \\
\hline
\end{tabular}

* Significant at a level of 0.05

\begin{tabular}{|c|c|c|c|c|}
\hline $\begin{array}{l}\text { Child value } \\
\text { dimen- } \\
\text { sions }\end{array}$ & $\begin{array}{l}\text { Minimum } \\
\text { obtained } \\
\text { score }\end{array}$ & $\begin{array}{l}\text { Maximum } \\
\text { obtained } \\
\text { score }\end{array}$ & $\begin{array}{l}\text { Standard } \\
\text { deviation }\end{array}$ & Average \\
\hline $\begin{array}{l}\text { Emotional } \\
\text { dimension }\end{array}$ & 2.57 & 5 & 0.42 & 3.79 \\
\hline $\begin{array}{l}\text { Economic } \\
\text { dimension }\end{array}$ & 1.67 & 4.5 & 0.52 & 3 \\
\hline $\begin{array}{l}\text { Social di- } \\
\text { mension }\end{array}$ & \begin{tabular}{|l|}
1.79 \\
\end{tabular} & 4.93 & 0.6 & 2.97 \\
\hline
\end{tabular}

Table 3. Chi-square test results of the relationship between demographic variables with variables of the value of child and postpartum depression

\begin{tabular}{|l|l|l|}
\hline Demographic variables & $\begin{array}{l}\text { Value of having } \\
\text { a child }\end{array}$ & $\begin{array}{l}\text { Postpartum } \\
\text { depression }\end{array}$ \\
\hline Mother's age & 0.925 & 0.746 \\
\hline Mother's job & 0.250 & 0.326 \\
\hline Father's job & 0.860 & 0.896 \\
\hline Mother's education & 0.187 & $0.046^{*}$ \\
\hline Father's education & 0.403 & 0.571 \\
\hline Economic situation & 0.820 & $0.012^{*}$ \\
\hline Housing situation & 0.507 & 0.189 \\
\hline Duration of marriage & 0.800 & 0.096 \\
\hline Type of pregnancy & Less than $0.001^{*}$ & Less than $0.001^{*}$ \\
\hline Delivery method & Less than $0.001^{*}$ & Less than $0.001^{*}$ \\
\hline
\end{tabular}

* Significant at a level of 0.05 .

Table 4. Comparison of percentage of postpartum depression, the value of having a child and its dimensions with maternal education in the studied women

\begin{tabular}{|l|l|l|l|l|l|}
\hline $\begin{array}{l}\text { Educational level of } \\
\text { mother }\end{array}$ & $\begin{array}{l}\text { Postpartum } \\
\text { depression }\end{array}$ & $\begin{array}{l}\text { Value of having } \\
\text { a child }\end{array}$ & $\begin{array}{l}\text { Emotional } \\
\text { dimension }\end{array}$ & Economic dimension & Social dimension \\
\hline Middle school & $0.71 \pm 0.47$ & $3.29 \pm 0.37$ & $3.90 \pm 0.39$ & $3.06 \pm 0.45$ & $3.09 \pm 0.53$ \\
\hline Diploma & $0.94 \pm 0.50$ & $3.21 \pm 0.48$ & $3.78 \pm 0.44$ & $3.02 \pm 0.53$ & $3.00 \pm 0.63$ \\
\hline Associate degree & $0.96 \pm 0.52$ & $3.20 \pm 0.41$ & $3.75 \pm 0.39$ & $2.98 \pm 0.48$ & $3.02 \pm 0.57$ \\
\hline Bachelor's degree & $0.80 \pm 0.50$ & $3.13 \pm 0.47$ & $3.80 \pm 0.44$ & $2.98 \pm 0.55$ & $2.87 \pm 0.59$ \\
\hline
\end{tabular}




Table 4. Comparison of percentage of postpartum depression, the value of having a child and its dimensions with maternal education
in the studied women
\begin{tabular}{|l|l|l|l|l|l|}
\hline $\begin{array}{l}\text { Educational level of } \\
\text { mother }\end{array}$ & $\begin{array}{l}\text { Postpartum } \\
\text { depression }\end{array}$ & $\begin{array}{l}\text { Value of having } \\
\text { a child }\end{array}$ & $\begin{array}{l}\text { Emotional } \\
\text { dimension }\end{array}$ & Economic dimension & Social dimension \\
\hline Master's Degree & $1.07 \pm 0.51$ & $3.15 \pm 0.50$ & $3.72 \pm 0.43$ & $2.93 \pm 0.56$ & $2.95 \pm 0.65$ \\
\hline$t$-Test stats & 26.574 & 25.401 & 3.928 & 22.034 & 34.417 \\
\hline$p$ & $0.046 *$ & 0.187 & 0.864 & 0.577 & 0.353 \\
\hline
\end{tabular}

* Significant at a level of 0.05 .

Table 4 shows the percentage of relation between postpartum depression, the value of a child and its dimensions with the mother's education. There was a significant relationship between the level of education and postpartum depression $(p=0.04)$, but no significant relationship was observed between the value of a child ( $p=0.18)$, emotional dimension $(p=0.86)$, economic dimension $(p=0.57)$ and social dimension $(p=0.35)$.

\section{Discussion}

The present study was conducted with the aim of evaluating the relationship between a child's value and postpartum depression in Bam city. The primary analysis of the data in this study showed that there was no relationship between postpartum depression and the emotional dimension of a child's value, but there was a significant relationship between the value of a child and the economic and social dimensions. In the present study, the highest average score of the child's value was related to the emotional dimension, which was consistent with the study conducted by Mayer et al. [21]. Although, in a study by Fazeli et al., the highest average was obtained for dimension of providing security when parents are old (social dimension) [22].

The reason for this contradiction can be explained in that perhaps in metropolises, due to the lack of attention to middleaged people and the lack of supporting organizations [17], this traditional vision of the child is of the utmost importance for women, which has made provision of security when parents are old a concern for Iranian women. However, in developed cultures, the profitable economic value is diminished [23-25], because little economic benefits are provided by children for their parents, while the emotional value of a child can be the primary reason for having a child [23].

In the present study, the family value of a child was more important among younger women than older women, but Mayer et al. showed that among three generations of one family, older generations paid more attention to the traditional dimension of a child's value (economic value and social) more than younger generations [21]. These differences can be attributed to the socio-cultural differences between two societies and the manner in which women were selected. In Mayer's et al. study, the comparison of the value of a child in one family was conducted, and members of a family were compared, but in the present study, the subjects were randomly selected. In the study of Fazeli et al., the family value of a child was reduced from older generations to younger generations, which is likely to be due to a change in the traditional family pattern in Iran relating to the economic and social changes in the country and the social status of women [22].

With an increase in the education of the husband and wife, material values (economic benefits) and intangible values (emotional benefits, self-improvement and family expansion and continuity), the amount of childbirth becomes lower. There is a consistency between studies that indicate that in less educated women, the understanding of the value of the economic benefits and the intangible values of children is more frequent. The findings of Klein and Eckhard indicated that women with higher education pay little attention to desirable economic aspects (economic benefits of having children). However, in these studies, the immaterial values of children were in conflict with each other [26].
Postpartum depression is a disorder associated with uncontrollable anxiety attacks, guilty feelings and obsessive thinking. In this disease, the mother loses her mental health and cannot establish an emotional relationship with her child [27]. The findings of this study showed that $36 \%$ of the subjects suffered from depression. This finding is consistent with the results of most other studies, i.e. $30-50 \%$ of the prevalence of depression [28-30]. In justifying this finding, the differences in the way this study was conducted compared to previous studies concerning depression, in terms of the type of used tools and the method of interpreting the score obtained from these tools, should not be ignored. However, the lifestyle of people in different provinces and existing social supports from family members for woman during pregnancy and after delivery can justify the lesser prevalence of depression among women after childbirth. Among the possible reasons for the occurrence of postpartum depression in primiparous women is the transition to the maternal stage and the low self-confidence of primiparous mothers in meeting the needs of the child.

In terms of education, there was a significant difference between the two depressed and non-depressed groups, with a higher percentage of people with higher education being in the non-depressed group. This is consistent with the results of a study conducted in the United States [31]. With an increase in education, depression is expected to decline relatively. This is because an increased level of education leads to increased awareness in men and women towards physical, mental and social rights and the needs of each other. Moreover, an increased level of education leads to increased understanding, cooperation and, possibly, increased family income, which all contribute to creating a healthy living environment.

Another study believed that the delivery method, such as the use of labor induction, delivery with forceps, epidural analgesia and cesarean section, is associated with an increase in the prevalence of postpartum depression [32], which is consistent with the present study.

One of the strengths of this study was the probabilistic and multi-stage sampling method of the study design, the division of the number of samples based on the target society in the city of Bam and the equal chance of selecting women. In addition, the sampling of healthy women (based on their health records or their self-declaration) was performed on women referred to the healthcare centers. This greatly improved the generalizability of the results and minimized the probability of bias. The importance of this issue in the country's policy-making and the lack of similar studies across the country are other strengths of this study.

\section{Limitations of the study}

One of the limitations of this study is its cross-sectional nature. Therefore, some future studies may be required to measure some variables. As another limitation of this study, the difference in the understanding of research units from the questions raised can be mentioned. Sampling was conducted only in urban areas of Bam city due to the problems and transportation cost of sampling, while rural areas were not studied.

\section{Suggestion}

It is suggested that future studies be carried both in rural and urban areas simultaneously. Given the decline in the num- 
ber of childbirths in the country, it is suggested that the structure of a child's value be considered in future studies in order to examine the various factors affecting family burden and fertility in Iran among groups with different religious, cultural and ethnic characteristics. Since all subjects in this study reported breastfeeding, this variable could not be investigated, and it is suggested that this factor be investigated in future studies.

\section{Conclusions}

We concluded that postpartum depression was influenced by the social and economic dimensions of a child's value and demographic factors. The concept of the value of a child is a culture dependent variable, and considering this, depression, especially postpartum depression, is closely related to cultural and social factors. Emphasis on the importance of increasing the readiness of mothers and their caregivers regarding the risk fac- tors of postpartum depression and the emphasis of nurses and midwives on the importance of family and society support and healthcare providers can be effective in preventing postpartum depression in regions with a high prevalence of postpartum depression.

However, in the geographic area of this study, in order to reduce postpartum depression, it is recommended to increase family support or support for spouses with these young primiparous women during childbirth, which increases their selfesteem and improves their transition to the maternal stage in better conditions. The findings of this study can pave the way for future studies.

Acknowledgments. This study was funded by the research assistant of Bam University of Medical Sciences. We hereby thank the deputy, the staff of the health centers in Bam and all the women who participated in this project for their cooperation and assistance of.

Source of funding: This work was funded by the Student Research Committee, Bam University of Medical Sciences, Bam, Iran. Conflicts of interest: The authors declare no conflicts of interest.

\section{References}

1. Tol W, Purgato M, Bass J, et al. Mental health and psychosocial support in humanitarian settings: a public mental health perspective. Epidemiol Psychiatr Sci 2015; 24(6): 484-494.

2. Ahmadinejad FSS, Tayebi N, Khatami M. Difference in gender and childbirth costs and their association with postpartum depression. IJWHR 2021; 9(1): 136-143, doi: 10.15296/ijwhr.2021.24.

3. Alipour Z, Lamiyan M, Hajizadeh E. [Sleep quality in late pregnancy and postpartum depression]. Iranian Journal of Obstetrics, Gynecology and Infertility 2011; 40: 39-47 (in Persian).

4. Lashkaripour K, Bakhshani NM, Hokmabadi S, et al. [Postpartum depression and related factors: a 4.5 months study]. Journal of Fundamentals of Mental Health 2012; 13(52): 404-412 (in Persian).

5. Shitu S, Geda B, Dheresa M. Postpartum depression and associated factors among mothers who gave birth in the last twelve months in Ankesha district, Awi zone, North West Ethiopia. BMC Pregnancy Childbirth 2019; 19(1): 435, doi: 10.1186/s12884-019-2594-y.

6. Gavin NI, Meltzer-Brody S, Glover V, et al. Is population-based identification of perinatal depression and anxiety desirable? A public health perspective on the perinatal depression care continuum. In: Milgrom J, Gemmill A, eds. Identifying perinatal depression and anxiety: Evidence-Based Practice in screening, psychosocial assessment, and management. Wiley-Blackwell Publishing, Inc.; 2015: 11-31.

7. Seimyr L, Welles-Nyström B, Nissen E. A history of mental health problems may predict maternal distress in women postpartum. Midwifery 2013; 29(2): 122-131.

8. Wee KY, Skouteris H, Pier C, et al. Correlates of ante- and postnatal depression in fathers: a systematic review. J Affect Disorders 2011; 130(3): 358-377.

9. Sadock BJ, Sadock VA. Kaplan and Sadock's synopsis of psychiatry: behavioral sciences clinical psychiatry. Philadelphia: Lippincott Williams and Wilkins; 2011.

10. Rafiee $\mathrm{B}$, Akbarzadeh $\mathrm{M}$, Asadi $\mathrm{N}$, et al. [Comparison of attachment and relaxation training effects on anxiety in third trimester and postpartum depression among Primipara women]. HAYAT 2013; 19(1): 76-88 (in Persian).

11. Sadock BJ, Sadock V. Kaplan \& Sadock's synopsis of psychiatry behavioral sciences. 10th ed. Vol. 2. Tehran: Arjmand; 2007.

12. Masoudnia E. [Relationship between perceived social support and risk of postpartum depression disorder]. IJN 2011; 24(70): 8-18 (in Persian).

13. Mayer B, Trommsdorff G. Adolescents' value of children and their intentions to have children: a cross-cultural and multilevel analysis. J Cross-Cult Psychol 2010; 41(5-6): 652-670.

14. Aghajanian A. Family and Family change in Iran. In: Hennon CB, Wilson SM. eds. Families in a global context. London: Routledge; 2008: 277.

15. Suckow J, Klaus D. Value of children in six culters. Brno: Masaryk University; 2002.

16. Albert I, Trommsdorff G, Lubiewska K. Do older mothers, younger mothers and adolescents in Germanyand Poland differ in their ideas about having children or not? A closer look at the negative Value-of-Childrenand its further implications. Workshop on "Value of Children and Intergenerational Relations". University of Konstanz. March 29th-30th, 2012.

17. Kazaryants K. Delayed motherhood, childbearing motivation and psychological distress levels in females age 30 and above [dissertation]. Los Angeles: Alliant International University; 2009.

18. Nauck B, Klaus D. The varying value of children: empirical results from eleven societies in Asia, Africa, and Europe. Curr Sociol 2007; 55: 487-503.

19. Shahnoushi M. [Sami majority. The value of children in urban and rural differences Semirom city]. Sociology 2013; 5(3): 75-96 (in Persian).

20. Mahdavy M, Kheirabadi G. The prevalence of postpartum depression and its related factors among women in Natanz city in 2018 (Iran). Qom Univ Med Sci J 2020; 14(2): 78-85.

21. Mayer B, Albert I, Trommsdorff G, et al. Value of children in Germany: dimensions, comparison of generations, and relevance for parenting. Konstanz: Bibliothek der Universität Konstanz; 2009.

22. Fazeli E, Gilmakani N, Taghipour A, et al. Relationship between value of children and fertility rate in womem referred to Mashhad helth centers. IJOGI 2014; 17(108): 21-27.

23. Nauck B. Value of children and the framing of fertility: results from a cross-cultural comparative survey in 10 societies. Eur Soc Rev 2007; 23(5): 615-629. 
24. Henz U. Gender roles and values of children: childless couples in East and West Germany. Demo Res 2008; 19: 1451-1500.

25. Mayer B, Trommsdorff G. Adolescents' value of children and their intentions to have children: a cross-cultural and multilevel analysis. J Cross Cult Psychol 2010; 41(5-6): 671-689, doi: 10.1177/0022022110372195.

26. Klein T, Eckhard J. Educational differences, value of children and fertility outcomes in Germany. Curr Sociol 2007; 55(4): 505-525.

27. Halbreich U, Karkun S. Cross-cultural and social diversity of prevalence of postpartum depression and depressive symptoms. J Affect Disord 2006; 91(2-3): 97-111, doi: 10.1016/j.jad.2005.12.051.

28. Alharbi AA, Abdulghani HM. Risk factors associated with postpartum depression in the Saudi population. Neuropsychiatr Dis Treat 2014; 17(10): 311-316.

29. Akbari SK, Vameghi R, Sajedi F, et al. Relationship between socio-economic status, perceived stress, social support and domestic violence with women's depression in reproductive age using path analysis. Iran J Health Educ Health Promot 2016; 3(4): 391-401.

30. Saei M, Mohaddesi H, Edalatnemun R. The predisposing factors of postpartum depression in women referring to selected health centers in Urmia in 2015. J Urmia Nurs Midwifery Fac 2017; 14(11): 918-925.

31. Centers for Disease Control and Prevention. Prevalence of self-reported postpartum depressive syndrome - 17 states, $2004-2005$. MMWR 2008; 57(14): 361-366.

32. Cowell W, Colicino E, Askowitz T, et al. Fetal sex and maternal postpartum depressive symptoms: findings from two prospective pregnancy cohorts. Biol Sex Differ 2021; 12(1): 6, doi: 10.1186/s13293-020-00348-x.

Tables: 4

Figures: 0

References: 32

Received: 21.06 .2020

Reviewed: 12.07 .2020

Accepted: 18.05.2021

Address for correspondence:

Naeimeh Tayebi, MSc

Department of Midwifery

Faculty of Nursing and Midwifery

Bam University of Medical Sciences

Bam

Iran

Tel.: +91 70618566

E-mail: tayebi_m67@yahoo.com 